\title{
Novel Segmented Roadside Plugging-Filling Mining Method and Overlying Rock Mechanical Mechanism Analyses
}

\author{
Wenqiang $\mathrm{Mu}{ }^{1,2}$, Lianchong $\mathrm{Li}^{1,2}, * \mathbb{0}$, Zhongping Guo ${ }^{3}$, Zhaowen $\mathrm{Du}^{3}$ and Sixu Wang ${ }^{1,2}$ \\ 1 Center of Rock Instability and Seismicity Research, School of Resources and Civil Engineering, Northeastern \\ University, Shenyang 110819, China; neumwq2017@163.com (W.M.); 1870860@stu.neu.edu.cn (S.W.) \\ 2 Key Laboratory of Ministry of Education on Safe Mining of Deep Metal Mines, Northeastern University, \\ Shenyang 110819, China \\ 3 Key Laboratory of Mine Disaster Prevention and Control, Shandong University of Science and Technology, \\ Qingdao 266590, China; gzp57046@126.com (Z.G.); qddzw3215@126.com (Z.D.) \\ * Correspondence: li_lianchong@163.com; Tel.: +86-138-9888-6235
}

Received: 5 May 2019; Accepted: 28 May 2019; Published: 30 May 2019

\begin{abstract}
The no-pillar mining method is widely used in coal mining engineering because of its superiority in resolving mine pressure hazards and protecting natural resources. In view of the geological conditions of stable strata in a coal mine of the Shandong Coal Zone, a novel segmented roadside plugging-filling mining method is proposed by introducing the filling coefficient into roadside filling. The operation process is designed with a new grouting filling forming device. Based on the relationship between the theoretical deflection of a cantilever beam and geometric settlement and parallel settlement models, strength formulas applicable to the segmented roadside plugging-filling (SRPF) method at different migration stages are obtained, and the deformation formulas of a roadway toward a rock slab are solved by an elastic equivalent model. Further, the determination procedure of the filling mode under the mining method is clarified. The SRPF method was implemented on a test stope, and the test results indicated that the theoretical deformation produced by the SRPF method was small and can meet the mining requirements. Through on-site test monitoring, the deformation of surrounding rock was $0-160 \mathrm{~mm}$ and the filling body under the SRPF method could maintain its own strength and the stability of the surrounding rock. In addition, entire successful mining been completed in the working stope, which further proves the applicability of this method. The backfilling cost of the gob-side filling was reduced by approximately $50 \%$, and the backfilling efficiency was improved in the mine. The description of the novel mining method may provide theoretical and practical guidance for coal mining in similar geological conditions.
\end{abstract}

Keywords: coal mining; gangue filling body; theoretical model; rock deformation; field observation

\section{Introduction}

Coal is one of the world's most important energy sources, and important basic industries (such as the iron, steel, and power generation industries) still rely on coal, which is the indispensable main energy for human development. However, coal resources create waste, and mining area pollution is becoming serious in coal mining. With the depletion of preferable coal resources, the mining depth increases significantly and strata behavior (such as rock bursts and rock caving) occurs frequently. In addition, because of the disadvantages of the original pre-mining method (mining with coal pillar) and postprocessing, the environment of a mining area is seriously polluted, such as in the eastern mining area in China (as shown in Figure 1). Conventional mining has made a great impact on ecological resources and production safety, and the harmonious and green development of mining engineering 
and ecology should be gradually improved [1-3]. Coal exploitation and protection methods face severe challenges, when considering a higher coal recovery rate, preventing mine disasters, reducing energy loss, eliminating mining area pollution, and realizing green, efficient mining.

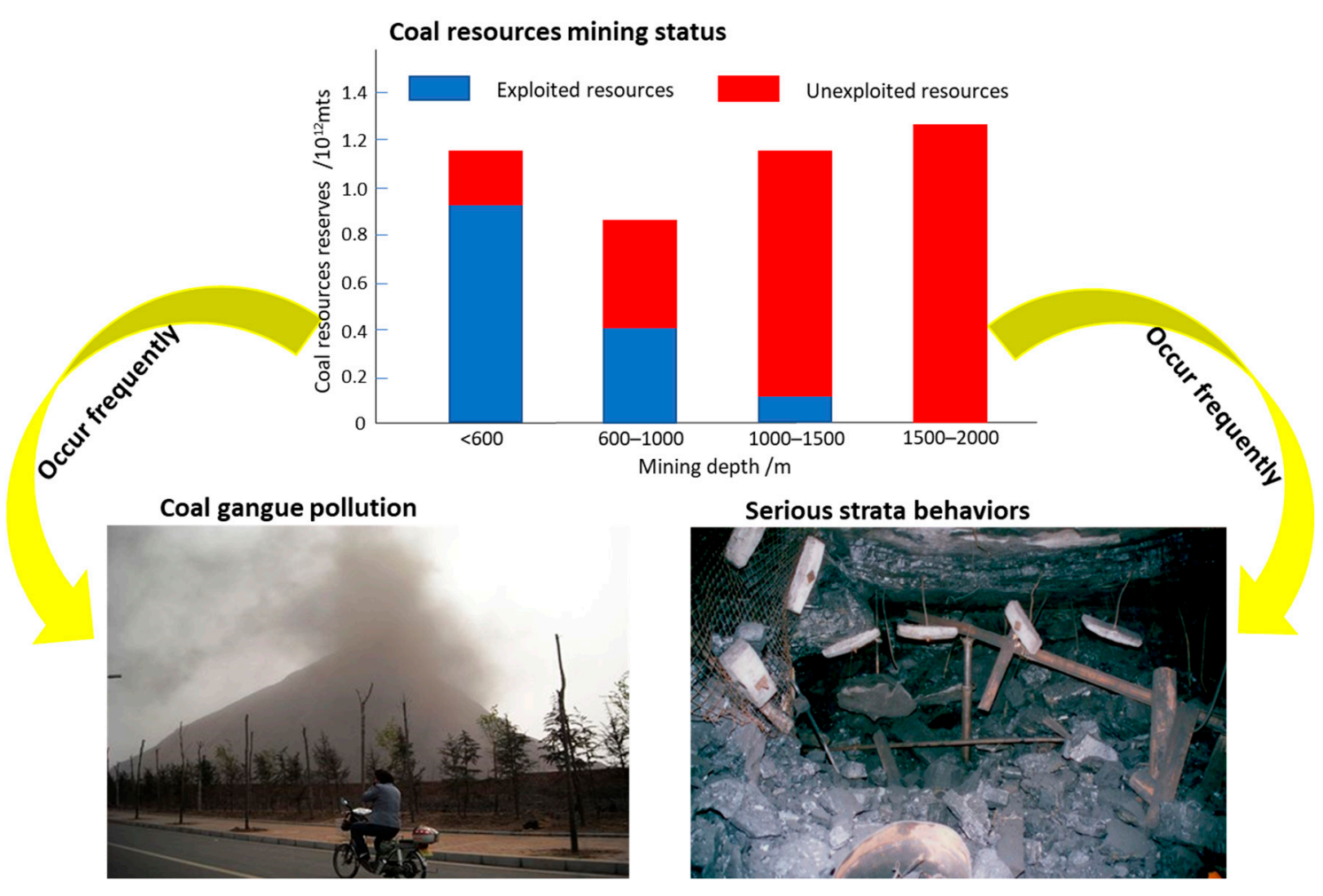

Figure 1. Urgent problems of coal resources.

For the green, efficient mining technology of a coal mine, many scholars at home and abroad have conducted a significant amount of research, and the gob-side entry retaining (GER) mining method is widely used in underground coal mining [4-6]. Owing to its high coal recovery rate and low roadway development rate in complex geological conditions, this method has prevailed in some countries, including China [7]. In the mining process, traditional protective pillars are deleted, the amount of roadway excavation is reduced, and the stope mechanics model formed by the original support mode is changed [8-12]. Geological dynamic hazards during coal mining can be caused by the structural instability of a composite system of roof rock and coal layers [13]. The stability of a roadway surrounding rock cannot rely entirely on the support in the roadway, so the support function beside the roadway must be used to control the roof stratum settlement [14]. Paste materials, such as cement material and high-water material, can be reinforced by grouting with formwork to create a roadside supporting wall, and a spatial mechanical model can be established to determine the main parameters of the paste roadside supporting body $[15,16]$. In order to solve the problems of waste hill pollution and high filling costs in mining areas (as shown in Figure 1), gangue material is gradually applied in filling mining [17-20].

The mechanical properties of a roadside filling body are different for the surrounding rock properties of a working face [21]. The requirements for retaining of gob-side entry in the stable strata of a medium-thick coal seam are relatively low, but are relatively high in conditions with a large mining height and high stress [22,23]. However, a roadside irrigated by ordinary materials cannot fully adapt to all surrounding rock deformation. Thus, many researchers are developing new grouting materials and pouring materials such as high-water materials and gangue material $[24,25]$. Especially in deep mining, hard roof conditions, other geological conditions, which can easily cause impact disasters, and a roadside support body should adapt not only to the load, but also to the deformation [26-28]. 
Mastering the surrounding rock deformation law of a gob-side retaining roadway is the key to the rational support design of a gob-side retaining roadway. This determines the success or failure of a gob-side retaining roadway. The stress state and deformation failure mechanism in coal mining should be obtained, so that different mining methods can be put forward according to the mining environment and geological conditions [29].

Zhang (2015) developed a new roadway layout scheme for GER in a high-gas long-wall caving face of a coal mine in China. This scheme realized the safe mining of a high-gas thick coal seam [30]. He $(2017,2018)$ analyzed a mechanics model of a stope and the properties of the surrounding rock, and noted that the self-bearing capacity of coal and rock combined with high-performance mechanical equipment could realize roadway support [31,32]. Aiming at long-wall mining, pillarless mining technology for an automatic forming gob-side retaining roadway was proposed to reduce the roadway excavation rate, excavation cost, and number of safety accidents, and to improve the resource recovery rate. However, this method has very high requirements for mechanical equipment. Tan (2015) designed a filling body with multistage deformation characteristics to support a hard roof, and realized an entry retaining wall along a gob side under a hard roof stratum [26,27]. Ning (2017) developed an innovative support structure of three anchor bolts and a steel strip for gob-side entry retention in steep coal seam mining, and realized safe mining [33]. On the premise of fully maintaining roadway stability, maintaining goaf tightness, and ensuring safe and efficient mining, a reasonable mining method should be put forward, and reasonable parameters should be determined based on an established effective mechanical model. Then, roadside construction quantity of goaf and filling material can be reduced to cut mining costs, which is the key to effective mine production.

Based on a coal mine in the Shandong mining area, a new method called segmented roadside plugging-filling (SRPF) based on an improved roadside filling mode is proposed to solve the production problem. The construction procedure of this method is designed, and a new roadside filling device with strong applicability is created. The mechanism between the filling strength, rock deformation, filling coefficient, and other parameters is studied based on established models. The specific implementation mode of SRPF in a test stope is established, and field monitoring is carried out. The results of the field test demonstrate that the roadway surrounding rock has small deformations and is stable, which ensures the safe mining of the working face and reduces the filling cost of the gob-side retaining roadway. Thus, the new method is considered a more appropriate mining method for this type of mine.

\section{Mining and Geological Conditions}

The present analysis was based on the mining and geological conditions of a mining stope in a coal mine in Shandong province in the eastern part of China, as shown in Figure 2. The content of gas and carbon dioxide in the entire mine is low. With the exhaustion of easily exploitable coal resources, the mining depth gradually increases to $\sim 600 \mathrm{~m}$. Owing to the disadvantages of the original mining technology in coal pillar mining, coal resources are significantly wasted and the recovery rate is low. The refuse discharge amount is large, and coal gangue is mostly accumulated in the mining area. The roof of the coal seam in the mining area is mostly stable. However, some roof caving disasters always occur and threaten the safety of mine production. The cost of roadway excavation of working face, maintaining roadways, and disposing gangue is very high every year. Under these conditions, it is very important to reduce the tunneling amount and maintain safety.

The main coal seam of working face No. 2 is $16^{\#}$, and the thickness is approximately $1.3 \mathrm{~m}$. The overburden depth is $\sim 520 \mathrm{~m}$, and the average dip angle is $4^{\circ}$. The immediate roof of the coal seam is limestone with a thickness of approximately $4.6 \mathrm{~m}$. The sequence of strata upward is mudstone, limestone, sandy mudstone, etc. The floor is arenaceous mudstone, limestone, $17^{\#}$ coal seam, and so on. The generalized stratigraphy is shown in Figure 3. The initial design mining method is a semi coal roadway with a gangue belt and single-prop combined support. The roof support effect is sufficient, but worker labor intensity is high, and the sealing of the goaf is poor. 


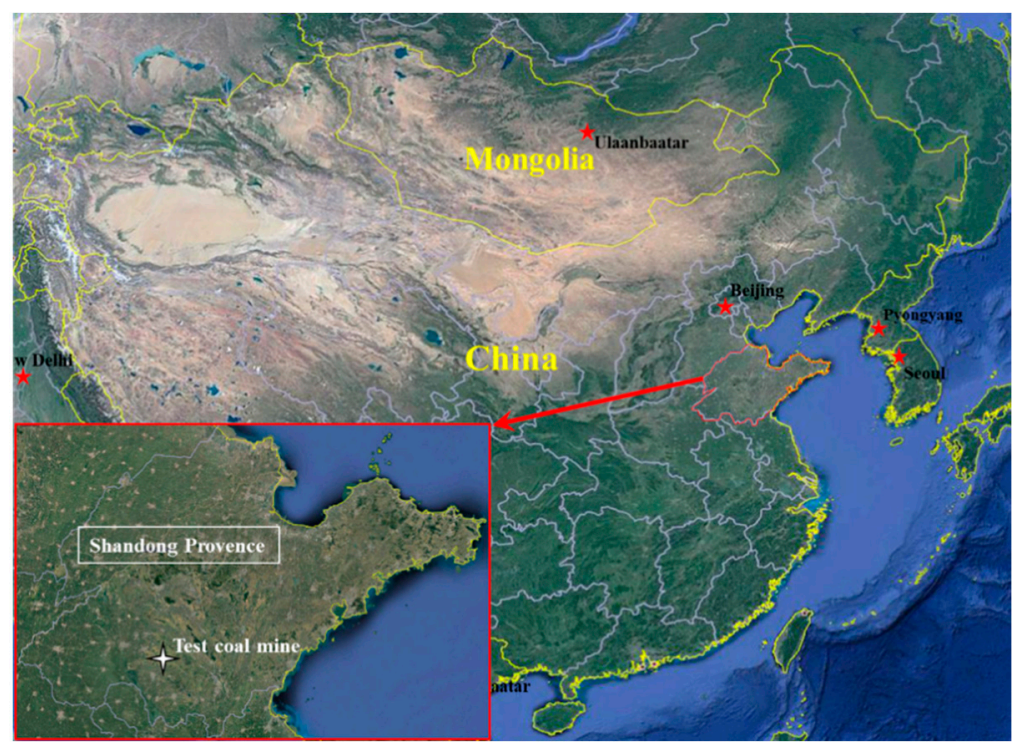

Figure 2. Schematic diagram of test stope.
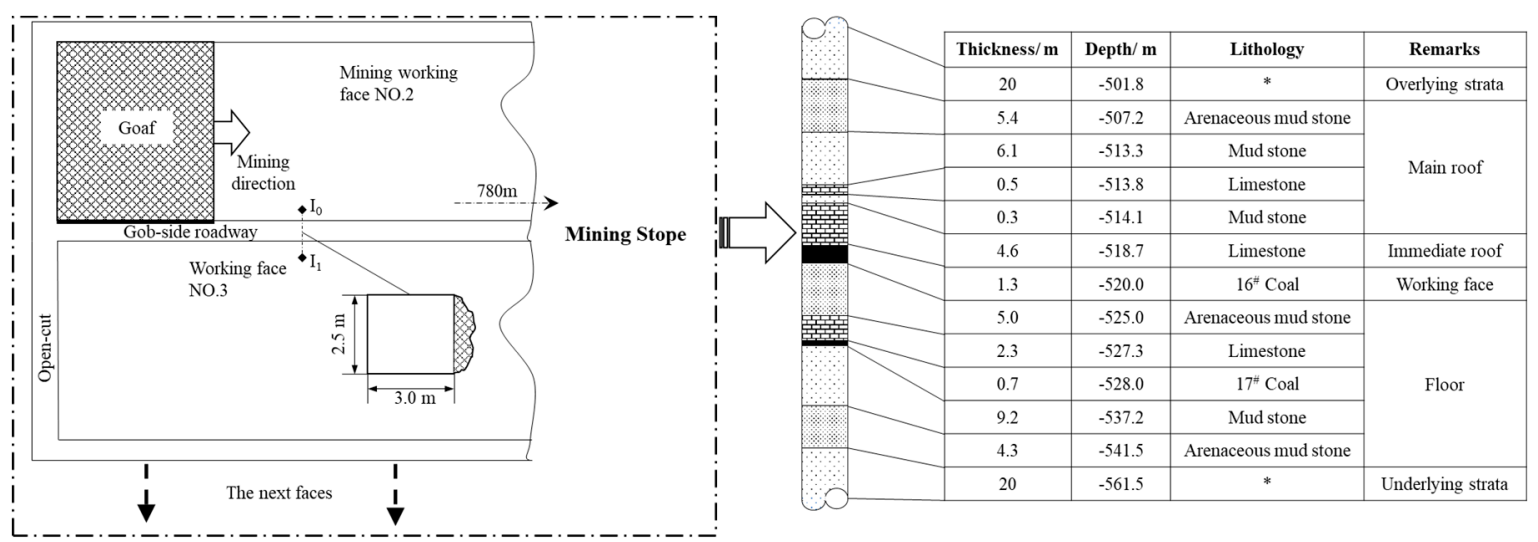

Figure 3. Mining stope and generalized stratigraphic diagrammatic sketch.

\section{Innovative Method SRPF for GER Mining}

\subsection{Conventional Forms for GER}

As an effective safe mining technology, waste of coal resources can be reduced and coal depletion problems can be solved with a no-pillar mining method. This can ensure working face safety with Y-type ventilation using the GER mining method, reduce the coal-rock layer shock risk, and decrease the occurrence of major safety accidents in coal mines. The no-pillar mining method (gob-side entry retaining) is illustrated in Figure 4.

WRF can be used with some limitations, including a good rock roof and coal seam conditions, in a mining space. The mining coal seam should be of medium thickness and the inclination angle should be small and without gas. At the same time, WRF is required to coordinate and cooperate with both the inner lane support and the roadside cut top. This method must be equipped with high-performance hydraulic support equipment, which results in higher costs. When applying this technology, to avoid the gangue moving into the roadway, wire mesh is set at the gob side, a single prop is used to support the roof cantilever beam and maintain the stability of the roadway, and a steel frame is set up to form natural gangue stacks, thus achieving safe entry. This is illustrated in Figure 4a. RF is widely used in mining to support the roof by using the roadside filling body to carry the overburden strata of the roadway, as illustrated in Figure $4 \mathrm{~b}$. However, RF always has a high 
material cost; thus, many researchers have studied on the material and filling width not only to ensure safe mine production but also to reduce the cost of the remaining lane along empty lanes.
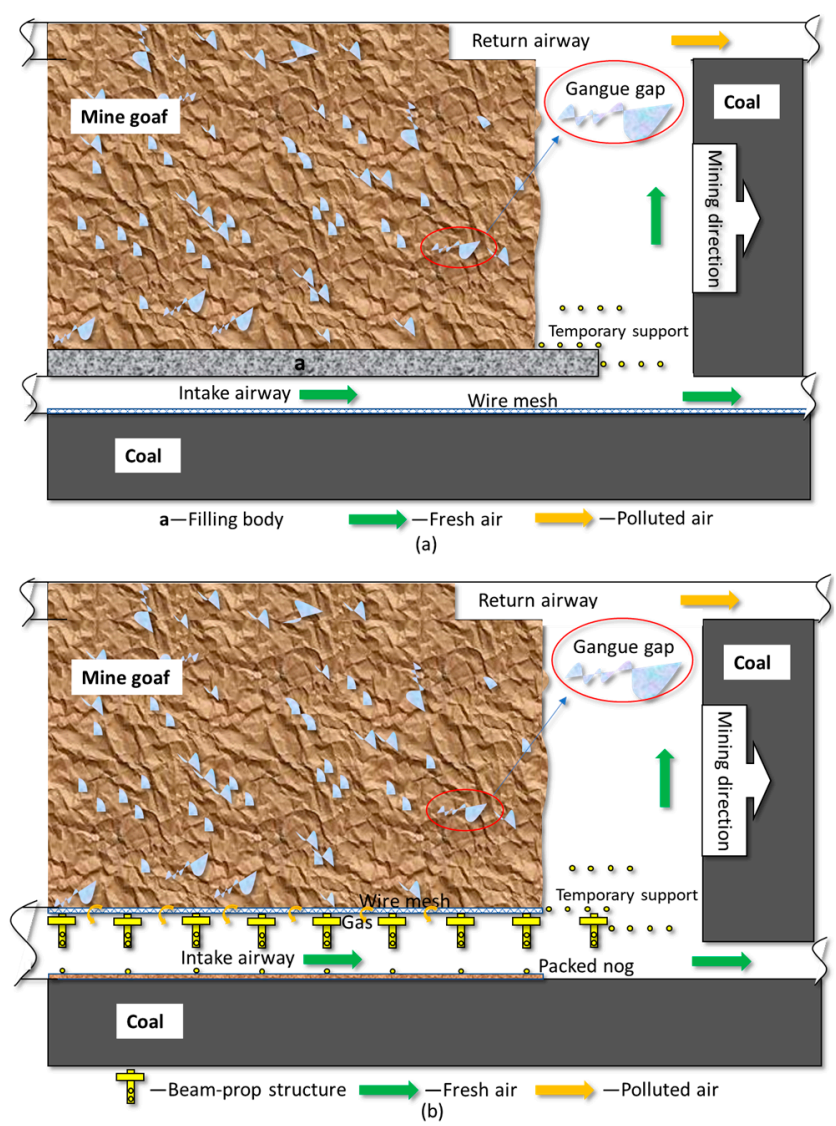

Figure 4. Schematic diagram of conventional mining method with gob-side entry: (a) gob-side entry retaining technology without roadside filling (GER-WRF) and (b) gob-side entry retaining technology with roadside filling (GER-RF).

According to previous research [34], the sensitivity of different factors to the deformation of the wall is different when the excavation of the ore body is left in the lane, that is, mining depth $>$ mining height $>$ length of working face $>$ roadway width, and filling height $>$ filling width $>$ filling coefficient. The mining depth and height, filling height, and width are the key factors in roadside retaining wall deformation and damage. When the goaf roof falls down after the coal seam is mined, the working face must follow the roadway adaptability supporting principle. The gangue contacts the floor and is gradually compacted. In addition, the entire supporting system can adapt to the roof caving though the combined action of the filling body, gangue, and coal. Therefore, considering mining costs and production safety, a new method for coal mining can be proposed by using the existing roadside filling and avoiding filling technology in order to reduce the cost. This method can ensure that mining safety meets the production needs of mine enterprises.

\subsection{Segmented Roadside Plugging-Filling Mining Method (SRPF)}

When the surrounding rock in the stope belongs to stable and good strata, such as limestone under low stress and sandstone, there is always redundancy of supporting structure and waste of filling materials with entire roadside filling body. In addition, large support equipment should be built in the use of gob-side retaining roadway without roadside body. SRPF is proposed considering the actual coal mining conditions, as illustrated in Figure 5. The filling body is built along the laneway trend, and the roadside support wall is divided into many columns to support the overlying strata. 
Each column is constructed with a new filling formwork. A sealing-exhaust wooden partition, where a configurable vent can be reserved for pre-extracting the gas of the goaf, is established for plugging between adjacent pairs of filling bodies. In the process of mining, artificial blasting should also be used to relieve the pressure of roof rock beam. To reduce costs, and coal gangue pollution in the mining area, cementing materials consisted of coal gangue particles, cement, fly ash, and so on are used to fill roadside.

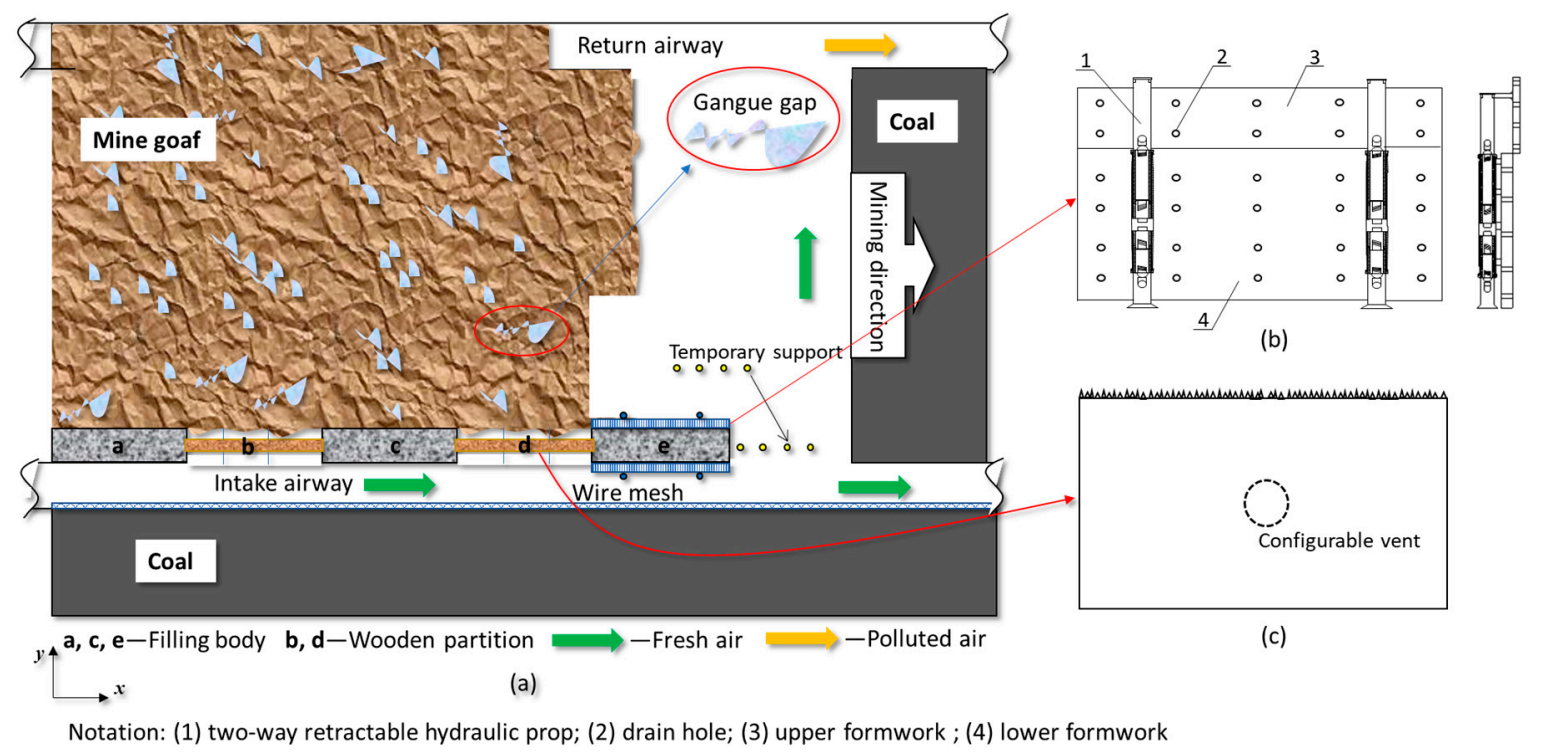

Figure 5. Schematic diagram of segmented roadside plugging-filling (SRPF): (a) roadway maintenance and ventilation during mining excavation in working face; (b) hydraulic fixed roadside filling device; and (c) sealing-exhaust wooden partition.

The performance of the supporting structure determines the surrounding rock stability, and the filling material is vital for the roadside filling body. The filling body should not only meet the load strength of the rock beam under the final position condition but should also adapt to the deformation caused by the slewing and sinking of the rock beam at the beginning of the surrounding rock movement. Therefore, gangue cementing material is added with a certain amount of foaming agent. Its purpose is to realize the control state of "given deformation, yielding" in the initial stage, and to ensure the "limited deformation, nonyielding" control state in the middle and late stages.

\subsection{Mining Process with New Device}

The mining progress with SRPF can be seen in Figure 6. After one cycle of coal seam mining, the equipment should be examined and repaired. The filling material is pumped into the space formed by the formwork using the filling pumping equipment after building temporary support. The slurry, which is mixed with gangue, cement, sand, and additives, is ready in the mixing station. The filling formwork and wooden partitions are assembled at the ground device station. The roadside is filled in one cycle of distance and plugged with a sealing-exhaust wooden partition in the next cycle after strengthening temporary support until the working face completely mined. First, however, various parameters (filling width, body strength, and filling coefficient) should be determined before mining operations begin. More details are covered in subsequent chapters. The filling coefficient is defined as the ratio of the length of all filling walls and the roadway length:

$$
\xi=\frac{n l_{b}}{D_{r}}=\frac{n l_{b}}{m l_{w}+n l_{b}}=\frac{1}{1+(m / n)\left(l_{w} / l_{b}\right)}
$$


where $\xi$ is the filling coefficient, $n$ is the number of filling bodies, $m$ is the number of plugging wooden partitions, $l_{b}$ is the unit body length, and $l_{w}$ is the unit plugging wooden partition length.

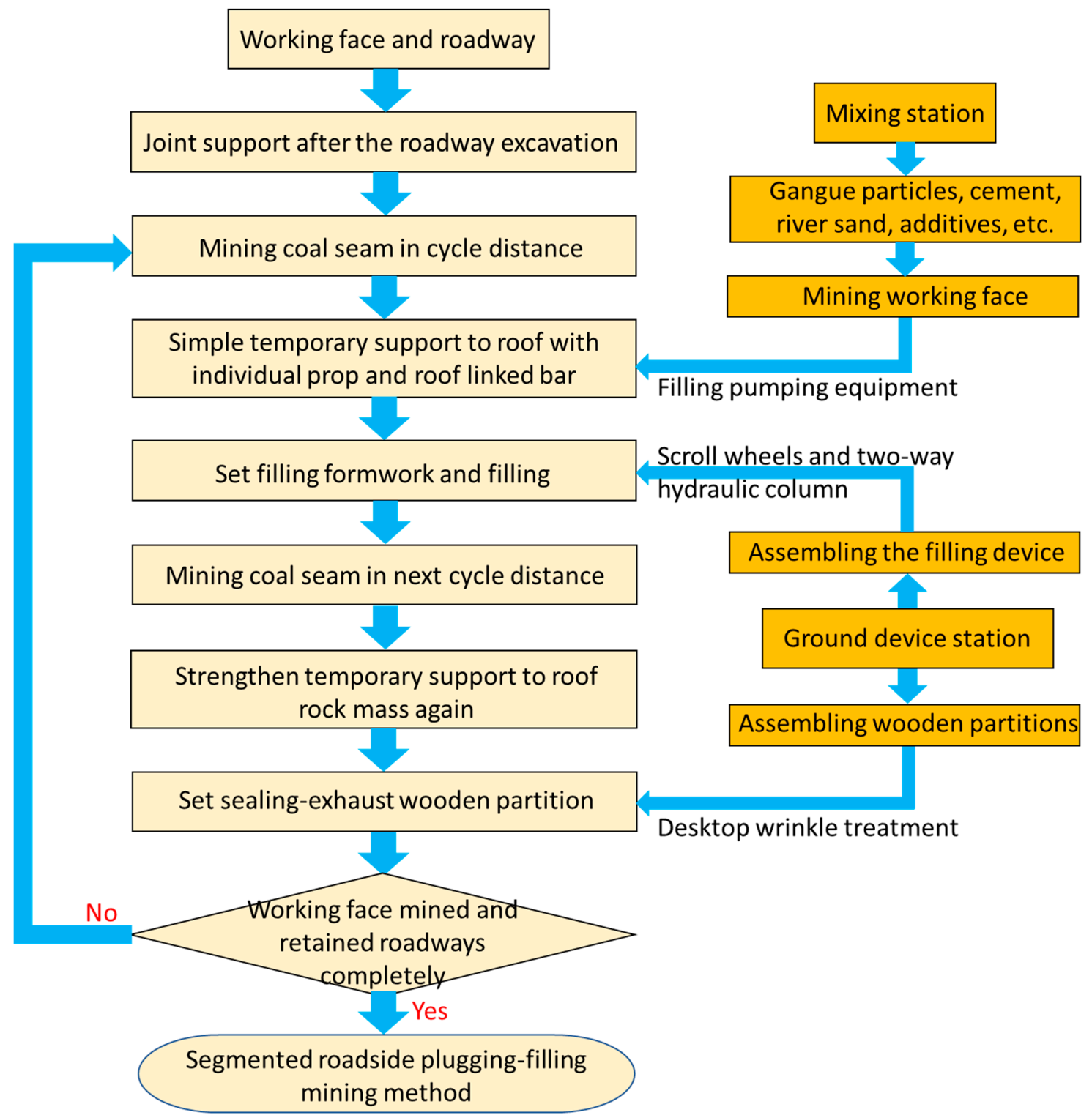

Figure 6. Mining process of SRPF.

The hydraulic fixed roadside filling device has three main components: a bidirectional retractable hydraulic prop, upper formwork, and lower formwork. This is illustrated in Figure 5. In time, water can seep out of the filling slurry from seepage holes left in the formwork. This can accelerate the filling material solidification and improve the progress of filling body strength. The hydraulic props used in this device adopt a bidirectional retractable design mode, which can increase the effect on the floor and roof rock mass and also fix the filling space instead of requiring additional temporary support. The upper and lower formwork and related parameters should be determined according to a stope mechanical model and structural parameters such as the mining height, cycle mining distance, and roadway size.

\section{Mechanical Mechanism of Overlying Rock}

In order to get the strength of the filling body, the stope model can be built to analyze theoretically considering the difference compared to previous methods. When mining a coal seam with the SRPF 
method, the stope spatial structure model formed in the stope is shown in Figure 7. Different from the traditional method of GER mining, the entire function of the filling body in a roadway strike is divided into multipoint support. The strike direction of the retained roadway (SDR) should be considered under this structure because of its multisegment support structure and suspended roof area. In the cross-sectional direction of the working face roadway (CSW), the mechanical model also changes. Each filling body changes into a bearing body that supports the upper rock strata and suspended roof. In Figure 7, the supporting function of the filling body ensures that the roadway can be formed stably in the mining stope.

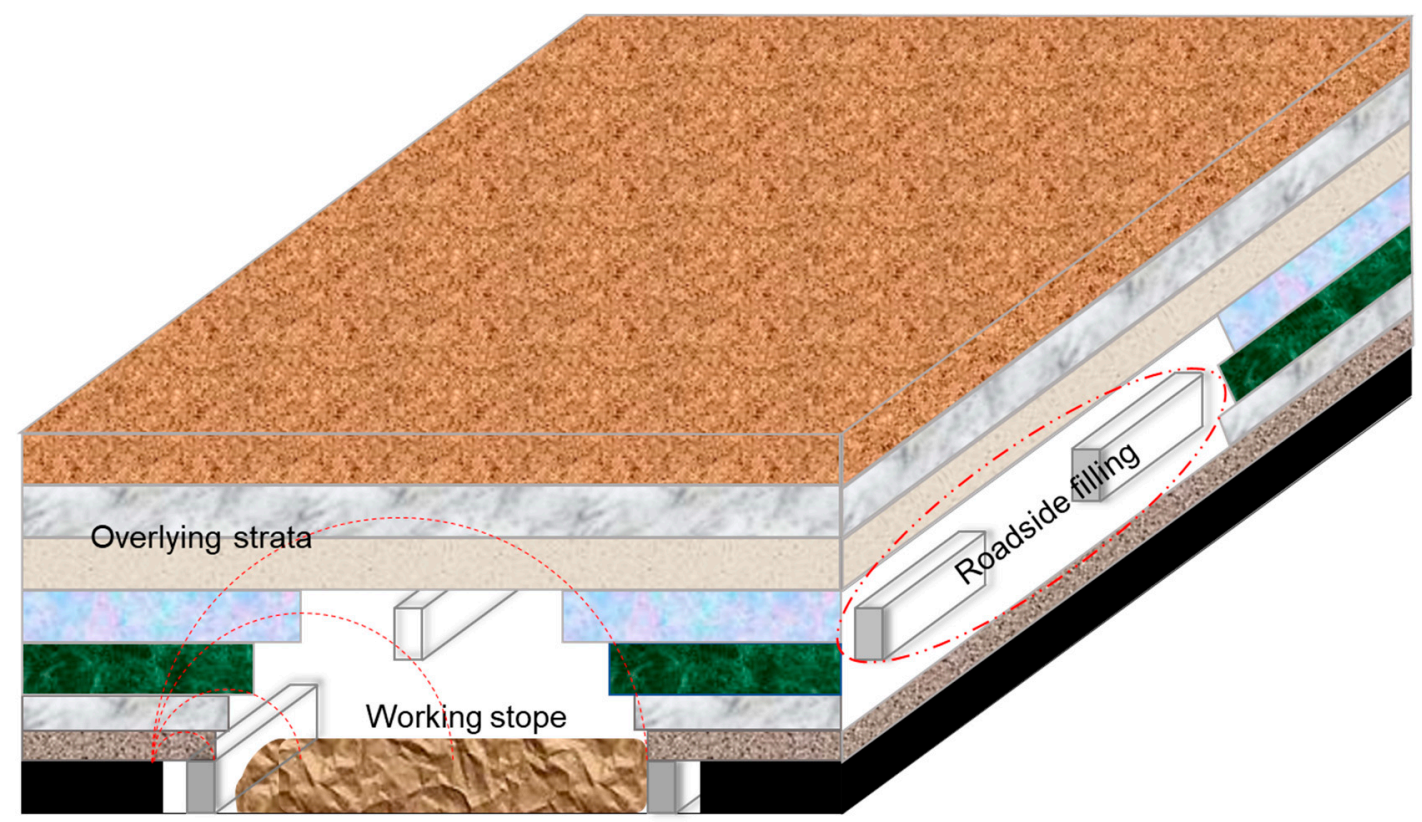

Figure 7. Stope mechanical model of load-bearing structural body.

\subsection{CSW Mechanical Strength Analysis at Different Stages}

According to the experimental model, the load of filling bodies can be analyzed in the section of roadway. During the use of gob-side entry retaining, the roof movement can be roughly divided into three stages: prophase movement, transitional movement, and postmovement [35]. In the prophase and transitional movements, the roof is mainly rotated and deformed and the subsidence amount is large. In the later movement, the roof deformation is mainly parallel subsidence, whose amount and speed are low. Among the three stages, the deformation of the filling body is the largest in the early stage. In this study, the two roof movement stages are defined as the initial and later stages.

(1) First, the long hanging roof is cut by blasting, and the roof of the pre-split working face collapses into the goaf $[36,37]$. Then, a mechanical analysis model of the SRPF method can be established based on the cantilever beam theory, as illustrated in Figure 8. In this initial stage, the residual support strength of the rock plate on the side of the goaf is not considered, and the rock beam is in the stage of rotational deformation. The entire mechanical model can be decomposed into three forms-i, ii, and iii-as shown in Figure 8. 


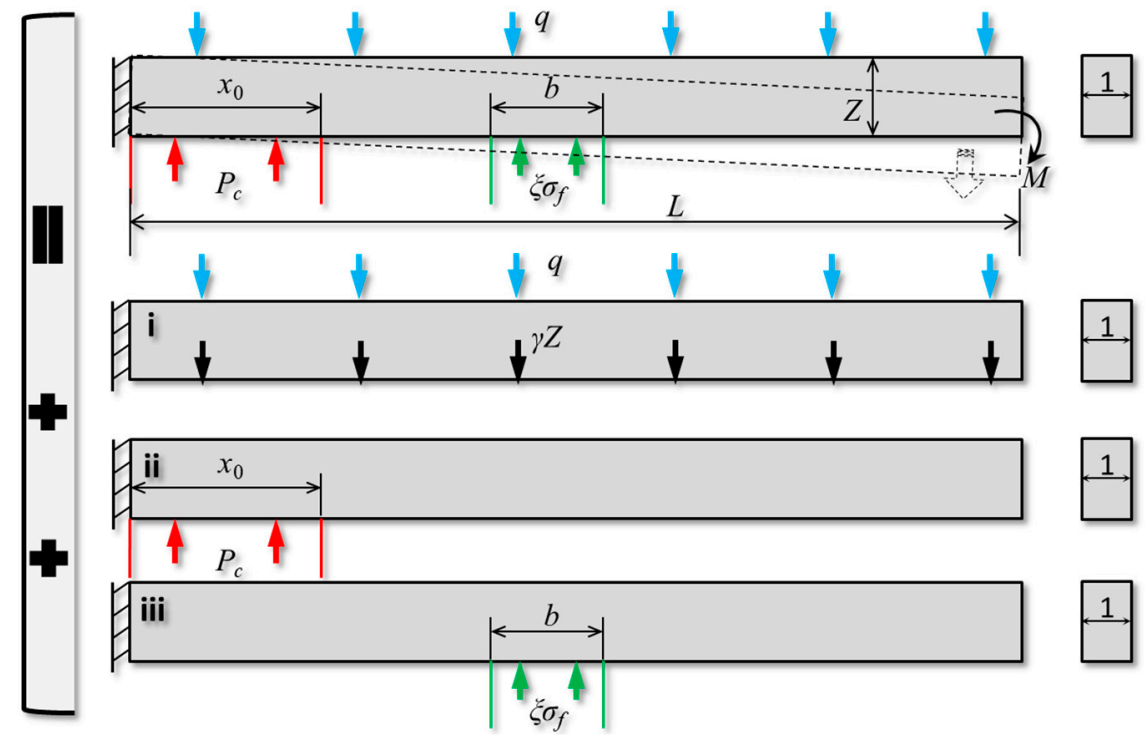

Figure 8. Initial mechanical model.

According to the unloading stress requirement of the working face roof [26], a certain deformation (the given deformation) of the roadway roof is allowed in the initial stage in the mining process of SRPF. The equations for the maximum deflection can be obtained based on the material mechanics. For form i, the maximum deflection can be calculated by

$$
w_{\max -\mathrm{i}}=\frac{(q+\gamma z) L^{4}}{8 E I}
$$

For form ii, the maximum deflection can be calculated by

$$
\left.\begin{array}{l}
w_{\max -\mathrm{ii}}=-\frac{P_{c} x_{0}^{3} L}{24 E I}\left(4-\frac{x_{0}}{L}\right) \\
x_{0}=\frac{h(1-\sin \varphi)}{2(1+\sin \varphi) \tan \varphi} \ln \frac{\left(k \sum_{i=1} \gamma_{i} h_{i}+C \cot \varphi\right)(1-\sin \varphi)}{(1+\sin \varphi) C \cot \varphi}
\end{array}\right\}
$$

For form iii, the maximum deflection can be calculated by

$$
\left.\begin{array}{l}
w_{\max -\mathrm{iii}}=-\frac{\xi \sigma_{f} r}{24 E I}\left[12 r^{2} L-4 r^{3}+(L-r) b^{2}\right] \\
r=x_{0}+d+b / 2
\end{array}\right\}
$$

where $P_{c}$ is the compressive strength of coal, $\sigma_{f}$ is the initial strength of the filling body, $q$ is the uniform load of the stratum, $L$ is the rotating deformation length of the rock beam, $x_{0}$ is the coal bearing distance, $b$ is the filling width, $d$ is the roadway width, $E$ is the elastic modulus of rock, $I$ is the polar moment of inertia, $C$ is the coal cohesion, $\varphi$ is the internal friction angle, and $\mathrm{d}$ is the roadway width.

Then, the maximum deflection of the mechanical model can be calculated by the following equation.

$$
w_{\max }=w_{\max -\mathrm{i}}+w_{\max -\mathrm{ii}}+w_{\max -\mathrm{iii}}
$$

In addition, in the process of continuous settlement and rock beam deformation movement, the roadside filling body will produce an obvious compression deformation. According to the theory of mine pressure and stratum control, combined with the geometric relationship between the rock beam deformation and goaf collapse gangue, the final settlement of the roof rock beam in the initial stage is as follows

$$
w_{\max }=\Delta h=h-h_{1}(\delta-1)
$$


Thus, the filling strength can be obtained:

$$
\sigma_{f}=\frac{3(q+\gamma Z) L^{4}-P_{c} x_{0}{ }^{3} L\left(4-\frac{x_{0}}{L}\right)-24 E I\left[h-m_{z}(\delta-1)\right]}{\xi r\left[12 r^{2} L-4 r^{3}+(L-r) b^{2}\right]}
$$

(2) In the later stage of the roof rock beam's parallel subsidence, the filling body should bear the roof pressure. The supporting structure in the roadway and connecting rock strata spanning backward have less force on the roof, which can be neglected. The roof experiences mainly parallel subsidence, but the subsidence amount and velocity are low. Thus, a mechanical model is established, as shown in Figure 9. The GER mining method forms arch-like structures in the overlying strata, and there is a strata fracture zone. When the advancing distance of the working face reaches the mining width, the development height of the "fracture arch" will reach $1 / 2$ of the working face width [38]. The mechanical equilibrium equation in the vertical direction is established along the section direction of the roadway. The main roof beam is subjected to uniform load $q_{N}$ from the overlying strata of the "fracture arch".

$$
\left.\begin{array}{l}
P_{c} x_{0}+\sigma_{f m} b \xi+P_{2} L_{X D}=\gamma_{1} h_{1} L_{z}+\gamma_{2} h_{2} L+q_{N} L \\
P_{2}=\frac{1}{2} \gamma_{2} h_{2}
\end{array}\right\}
$$

where $L_{X D}$ is the hanging roof length, $\sigma_{f m}$ is the long-term strength of the filling body, and $P_{2}$ is the support resistance of the gangue. The long-term strength of the filling body can be calculated by the following equation.

$$
\sigma_{f m}=\frac{k\left(\gamma_{1} h_{1} L_{z}+\gamma_{2} h_{2} L+q_{N} L-P_{c} x_{0}-\frac{1}{2} \gamma_{2} h_{2} L_{X D}\right)}{\xi b}
$$

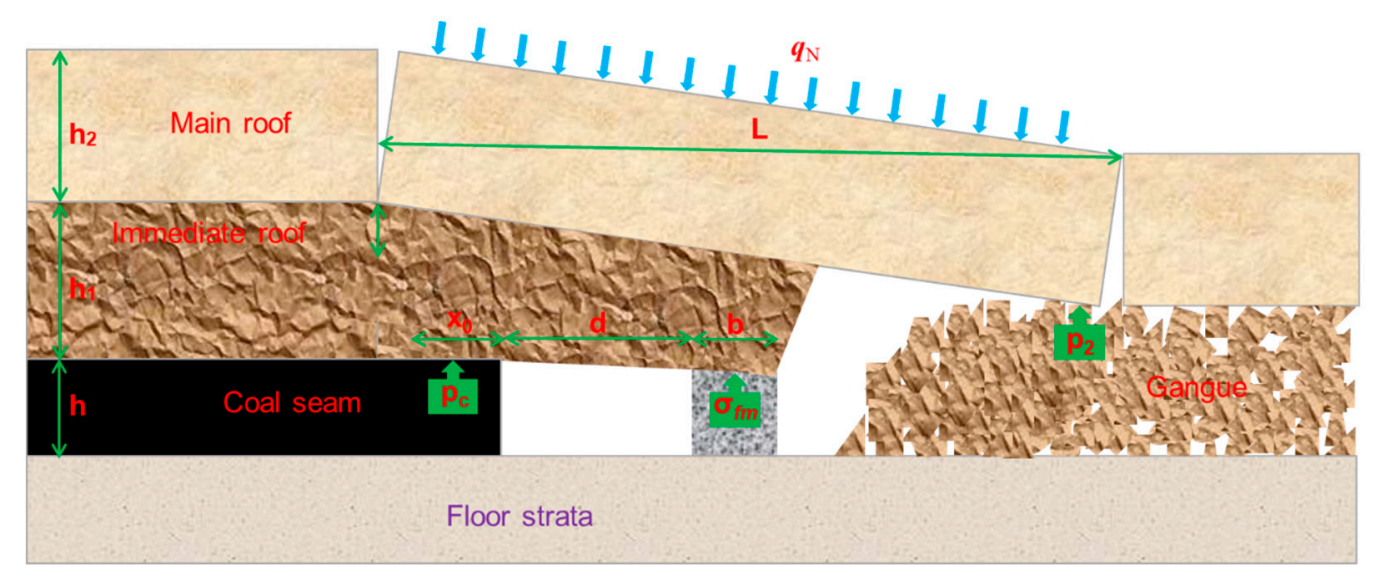

Figure 9. Later mechanical model.

\subsection{SDR Mechanical Analysis}

Due to the optimization of filling parameters, the mechanical model of filling unit in stope is changed. The hanging roof is approximately simplified as an elastic rectangular plate with a fixed boundary. Based on the plate and shell theory, the overlying rock formation of the gob area and roadway can be regarded as a fixed-boundary elastic rectangular sheet to analyze its stability. A model is established in Figure 10. 


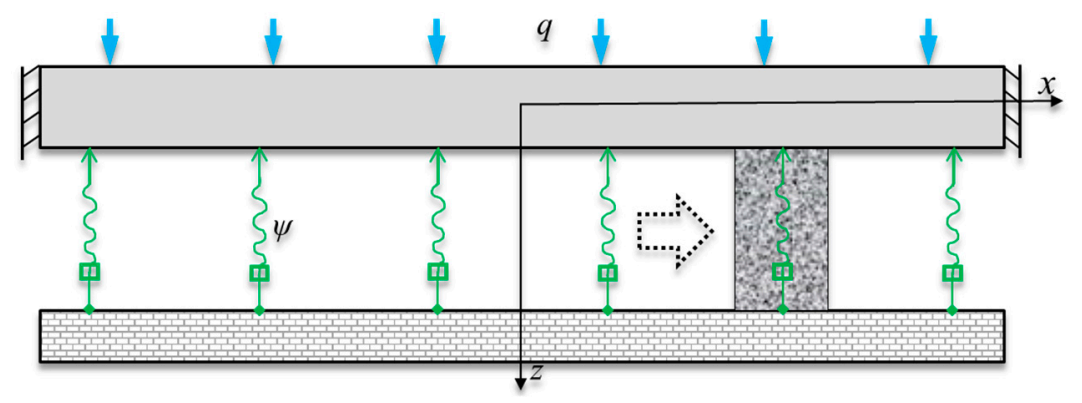

Figure 10. Mechanical model of filling-roof plate system.

In addition, assuming that the filling bodies are distributed equidistantly, each filling body can be expressed with an elastoplastic model with a spring of elastic modulus $E_{f}$. When the filling body has an equidistant distribution, these equidistant backfills can be approximately equivalent to the Winkler elastic foundation with a continuous distribution, and the equivalent elastic coefficient is $\psi$.

$$
\psi=\frac{n E_{f} l_{b} b}{4 X Y H_{f}}
$$

Based on the definition of the filling coefficient, Equation (10) can be further simplified as

$$
\psi=\frac{\xi E_{f} b}{2 Y H_{f}}
$$

It is assumed that the system can reach the equilibrium state after experiencing a consistent displacement deflection $w$ for the rock stratum and filling body. According to the geometric equations of elastic rigid body displacement, after ignoring the deformations of $\tau_{z x}, \tau_{z y}$, and $\sigma_{z}$, the physical equation can be obtained with deflection $w$. For the functional relationship between the deformation component and the deflection, the stress components $\sigma_{x}, \sigma_{y}$, and $\tau_{x y}$ can be expressed by deflection $w$ [39].

$$
\left.\begin{array}{l}
\sigma_{x}=\frac{E}{1-\mu^{2}}\left(\varepsilon_{x}+\mu \varepsilon_{y}\right) \\
\sigma_{y}=\frac{E}{1-\mu^{2}}\left(\varepsilon_{y}+\mu \varepsilon_{x}\right) \\
\tau_{x y}=\frac{E}{2(1+\mu)} \gamma_{x y}
\end{array}\right\}+\left\{\begin{array}{l}
\varepsilon_{x}=\frac{\partial u}{\partial x}=-\frac{\partial^{2} w}{\partial x^{2} z} \\
\varepsilon_{y}=\frac{\partial v}{\partial y}=-\frac{\partial^{2} w}{\partial y^{2}} z \\
\gamma_{x y}=\frac{\partial v}{\partial x}+\frac{\partial u}{\partial y}=-2 \frac{\partial^{2} w}{\partial x \partial y} z
\end{array} \Leftrightarrow\left\{\begin{array}{l}
\sigma_{x}=-\frac{E z}{1-\mu^{2}}\left(\frac{\partial^{2} w}{\partial x^{2}}+\mu \frac{\partial^{2} w}{\partial y^{2}}\right) \\
\sigma_{y}=-\frac{E z}{1-\mu^{2}}\left(\frac{\partial^{2} w}{\partial y^{2}}+\mu \frac{\partial^{2} w}{\partial x^{2}}\right) \\
\tau_{x y}=-\frac{E z}{1+\mu} \frac{\partial^{2} w}{\partial x \partial y}
\end{array}\right\}\right.
$$

Then, according to the relationship of the stress components and boundary conditions, the stress components $\tau_{z x}, \tau_{z y}$, and $\sigma_{z}$ can be expressed by deflection $w$.

$$
\left.\begin{array}{l}
\frac{\partial \tau_{z x}}{\partial z}=-\frac{\partial \sigma_{x}}{\partial x}-\frac{\partial \tau_{y x}}{\partial y} \\
\frac{\partial \tau_{z y}}{\partial z}=-\frac{\partial \sigma_{y}}{\partial y}-\frac{\partial \tau_{x y}}{\partial x}
\end{array}\right\} \Rightarrow\left\{\begin{array}{c}
\tau_{z x}=\frac{E}{2\left(1-\mu^{2}\right)}\left(z^{2}-\frac{Z^{2}}{4}\right) \frac{\partial}{\partial x} \nabla^{2} w \\
\tau_{z y}=\frac{E}{2\left(1-\mu^{2}\right)}\left(z^{2}-\frac{Z^{2}}{4}\right) \frac{\partial}{\partial y} \nabla^{2} w
\end{array}\right\} \Rightarrow \frac{\partial \sigma_{z}}{\partial z}=\frac{E}{2\left(1-\mu^{2}\right)}\left(\frac{Z^{2}}{4}-z^{2}\right) \nabla^{4} w
$$

After integration, the formula under an inner uniform load can be obtained according to the upper and lower boundary conditions. Thus, the mechanical equilibrium equations can be established.

$$
\overbrace{\left[\begin{array}{l}
D=E z^{3} /\left[12\left(1-v^{2}\right)\right], \nabla^{2}=\frac{\partial^{2}}{\partial x^{2}}+\frac{\partial^{2}}{\partial y^{2}} \\
q_{D}=q+\rho g z, T=\psi w
\end{array}\right]}^{D \nabla^{4} w+T=q_{D}}
$$

where $D$ is the flexural strength of the slab, $\nabla^{2}$ is the Laplace operator, $q_{D}$ is the total load acting on the filling body, $T$ is the load borne by the filling body, $v$ is Poisson's ratio of the slab, and $E_{f}$ is the elastic modulus of the filling body. 
The roof is a fixed boundary condition before failure that follows Equation (15):

$$
\begin{array}{ll}
\left.w\right|_{x= \pm X}=0 & \left.w\right|_{y= \pm Y}=0 \\
\left.w_{x}\right|_{x= \pm X}=0 & \left.w\right|_{y= \pm Y}=0
\end{array}
$$

According to the subsidence displacement of the roof and the boundary constraints, the approximate assumption is that the deflection has the following analytical solution form.

$$
\begin{aligned}
& w=w_{0}\left(x^{2}-X^{2}\right)^{2}\left(y^{2}-Y^{2}\right)^{2} / X^{4} Y^{4} \\
& w_{0}=w(0,0)
\end{aligned}
$$

where $w_{0}$ is the maximum subsidence displacement. Under the boundary conditions, the maximum settlement displacement of the roof can be obtained with Equation (17):

$$
w_{0}=\frac{441 q_{D}}{128\left\{2\left(\xi E_{f} b / 2 Y H_{f}\right)+9\left\{E z^{3} /\left[12\left(1-v^{2}\right)\right]\right\}\left[7 / X^{4}+4 /(X Y)^{2}+7 / Y^{4}\right]\right\}}
$$

Under the boundary condition of fixed support on the four sides, the maximum settlement displacement of the roof can be obtained by Equation (17). The deformation is directly related to the mechanical properties of the filling body.

\subsection{Segmented Roof Deformation}

Compared with other mining methods, this method has the greatest characteristic that there is a suspended roof between filling bodies. A restrained-beam model under the condition of an evenly distributed load is formed for the segmented roof. Assuming that the length of the rock beam is $2 l$, and both ends are constrained in the directions of $x$ and $z$, the mechanical model is shown in Figure 11 . The failure of the reserved suspended roof is analyzed without considering the overall settlement of the rock beam. The main failure mode of the reserved suspended roof is the bending-tension failure in the middle of the rock beam. The deformation of the rock beam is further analyzed.

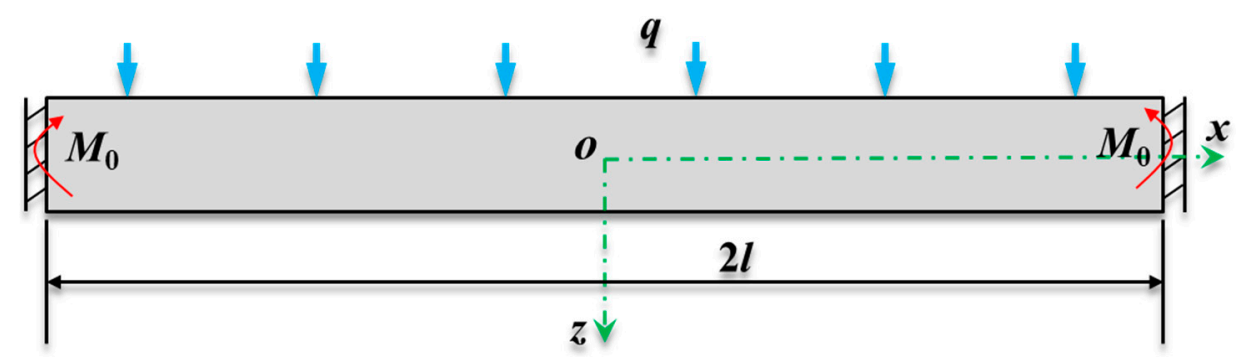

Figure 11. Segmented roof deformation.

For the rock beam, based on the mechanical model, the equations of each physical component in a fully elastic isotropic body are as follows according to elastic mechanics [40]. Therefore, the general formulas of the displacement component of a rectangular beam section under pure bending can be obtained.

$$
\left.\begin{array}{l}
D_{h}=\frac{M}{E I} x z-w z+D_{h 0} \\
D_{v}=-\frac{v M}{2 E I} z^{2}-\frac{M}{2 E I} x^{2}+w x+D_{v 0}
\end{array}\right\}
$$


Without considering the overall downward displacement, it is assumed that there is neither horizontal nor vertical displacement at both ends of the beam, so the boundary conditions are as follows

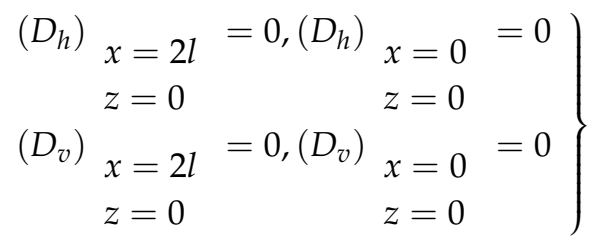

where $M$ is the moment, $I$ is the polar moment of inertia, and $2 l$ is the beam length.

The deflection equation of the beam (segmented roof) can be obtained as

$$
\left(D_{v}\right)_{z=0}=-\frac{M}{2 E I}\left(x-l_{w}\right)^{2}+\frac{M l_{w}^{2}}{2 E I}
$$

where $l_{w}$ can be calculated by using the filling coefficient $\xi$ and retaining distance $D_{r}$, and the maximum bending moment $M$ of the restrained beam can be calculated by using $q, l$, and the roadway width $d[39,40]$. Thus, the maximum deformation for the segmented roof can be obtained:

$$
\left(D_{v}\right)_{\max }=\frac{3 q d D_{r}^{4}}{128 E I}\left(\frac{\xi}{n}\right)^{4}
$$

For different stages of roof collapse in stope, the strength of filling body can be obtained by substituting the geomechanical parameters into Equations (7) and (9). The maximum deflection of the rock beam along the roadway can be calculated by Equation (17), but the value is the theoretical reference value after the support system is stabilized, which is certainly different from the field. In addition to the overall settlement of the rock beam, a certain amount of deformation will also occur in the segmented roof. The deformation value can be obtained by Equation (21).

\section{Field Application}

SRPF was conducted in the test field of the main transportation roadway of the 163-No. 2 working face in the coal mine. The main parameters of the test stope are illustrated in Table 1 . The length of the selected test section was $200 \mathrm{~m}$. Simultaneously, to verify the rationality of the mining method, mine pressure observation was carried out along the gob-side roadway in the test section. The purpose was to master the law of surrounding rock movement, obtain the mechanism of action between filling body and rock beam, determine the force and deformation of filling body beside the interval roadway, and determine the effect of retaining roadway.

Table 1. Main parameters of the test stope.

\begin{tabular}{ccccccc}
\hline Parameters & $L_{Z} / \mathbf{m}$ & $L / \mathbf{m}$ & $q / \mathbf{M P a}$ & $\boldsymbol{P}_{c} / \mathbf{M P a}$ & $I / \mathbf{m}^{4}$ & $x_{0} / \mathbf{m}$ \\
\hline Value & 8.5 & 22 & 13.6 & 1.3 & 158.88 & 1.21 \\
\hline Parameters & $\boldsymbol{E} / \mathrm{GPa}$ & $\boldsymbol{q}_{n} / \mathbf{M P a}$ & $\gamma / \mathbf{N} / \mathbf{m}$ & $\boldsymbol{L}_{X D} / \mathbf{m}$ & $\boldsymbol{C} / \mathbf{M P a}$ & $\delta$ \\
\hline Value & 16.7 & 0.99 & 2600 & 13.5 & 2.4 & 1.25 \\
\hline
\end{tabular}

\subsection{Calculation Results}

The material ratio determines the performance index of the filling material [41]. In the test area, filling material with rapid initial strength growth is required. According to previous studies and the underground pressure theory [42], the roadside filling body (filled with water, cement, and gangue waste at a ratio of $0.5: 1: 3$ ) has a height of $1.3 \mathrm{~m}$. Through a strength test of filling block at different ages in a laboratory, the strength change of the roadside support with time was obtained by Ning, as shown 
in Figure 12. The equivalent elastic modulus is $2.5 \mathrm{GPa}$. The gangue cemented filling body is grouted with an equidistant uniform distribution in the roadway.

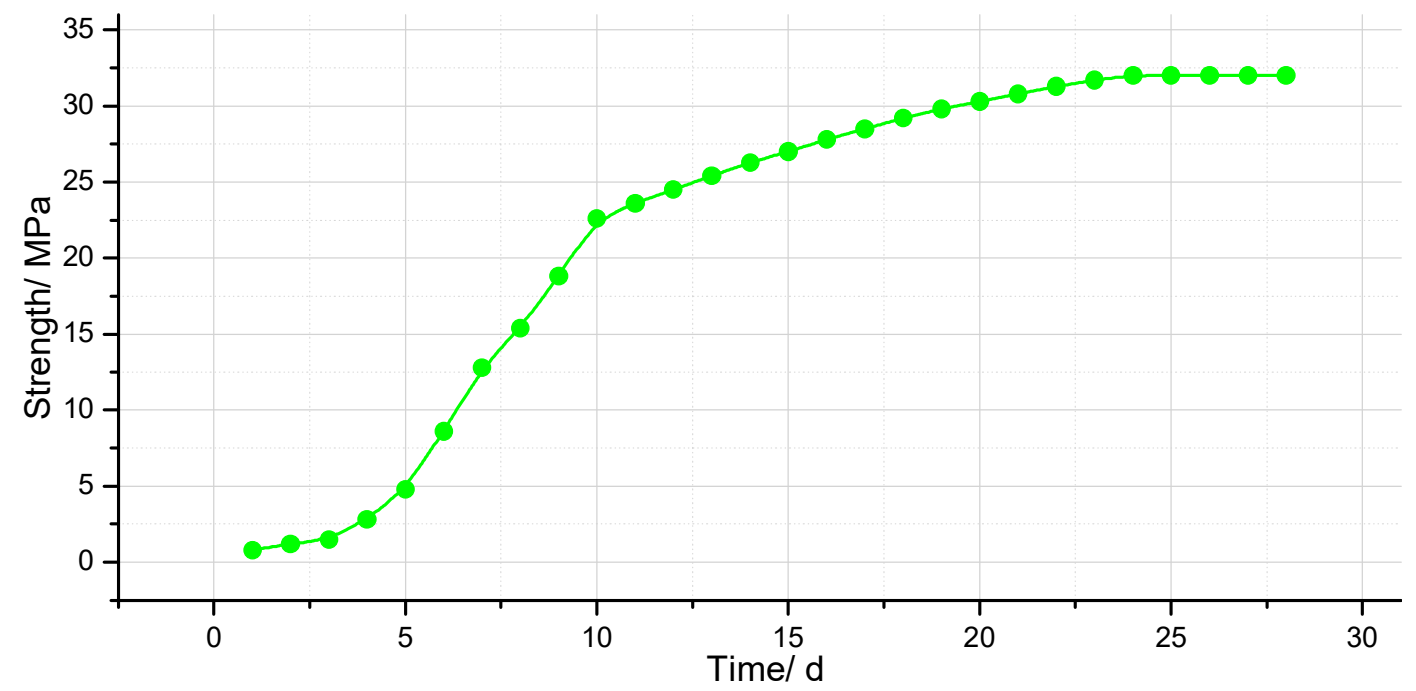

Figure 12. The strength change of filling body.

The calculated strength of the filling body is shown in Figure 13. According to the demands of mine production, the filling body is required to realize the initial effect on the roof in 7 days. Based on the strength trend of the filling body, the initial strength is $15.4 \mathrm{MPa}$. The strength becomes $32 \mathrm{MPa}$ in 24 days. Therefore, taking these two values as threshold values, the filling width and filling coefficient that can be satisfied under different strength requirements can be determined as follows

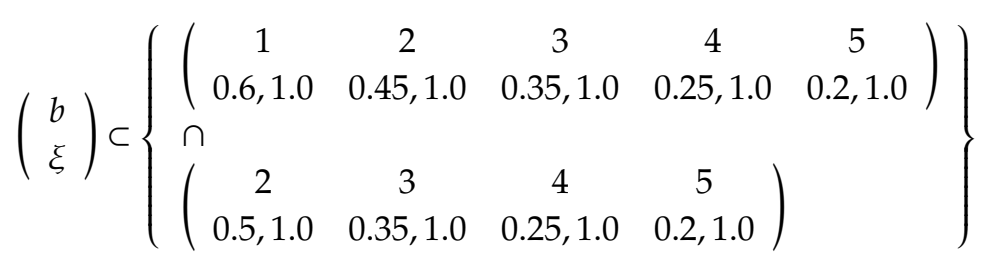

Then, a reasonable value can be obtained:

$$
\left(\begin{array}{l}
b \\
\xi
\end{array}\right) \subset\left(\begin{array}{cccc}
2 & 3 & 4 & 5 \\
0.5,1.0 & 0.35,1.0 & 0.25,1.0 & 0.2,1.0
\end{array}\right)
$$

Based on the internal stress field theory under the stope model and the mine requirement, a width of $2 \mathrm{~m}$ and filling coefficient of 0.5 can be selected as the optimal scheme when considering low-cost conditions and one day of the coal mining process. In addition, according to daily mining progress and the filling irrigation process, the length of filling body per unit is determined to be $2 \mathrm{~m}$.

Ignoring the supporting effect in the roadway, an initial strength of the filling coefficient of 0.5 and a ratio of filling to interval distance of 2:2 $\mathrm{m}$ are calculated by Equation (7). The strength is about 14.48 MPa. Compared with Figure 11, the strength of the roadside filling body can obtain a value of 15.4 MPa in 8 filling days. In the later stage, the strength of the filling body is calculated by Equation (9). The strength is $\sim 31.3 \mathrm{MPa}$ considering the stress concentration. Compared with Figure 12, the strength of roadside filling body can reach a value of $31.3 \mathrm{MPa}$ at 22 filling days. The strength of the filling body can ensure the stability of the roadway surrounding rock.

After choosing the filling material, for the deformation in the strike direction of the roadway, after the entire retaining roadway mining system is completed, the settlement displacement of entire roadway is calculated using Equation (17). The maximum roof settlement deformation is $\sim 38 \mathrm{~mm}$ 
after stability of support system, and for the segmented roof deformation, the separated maximum is $\sim 0.0058 \mathrm{~mm}$, which can be neglected.
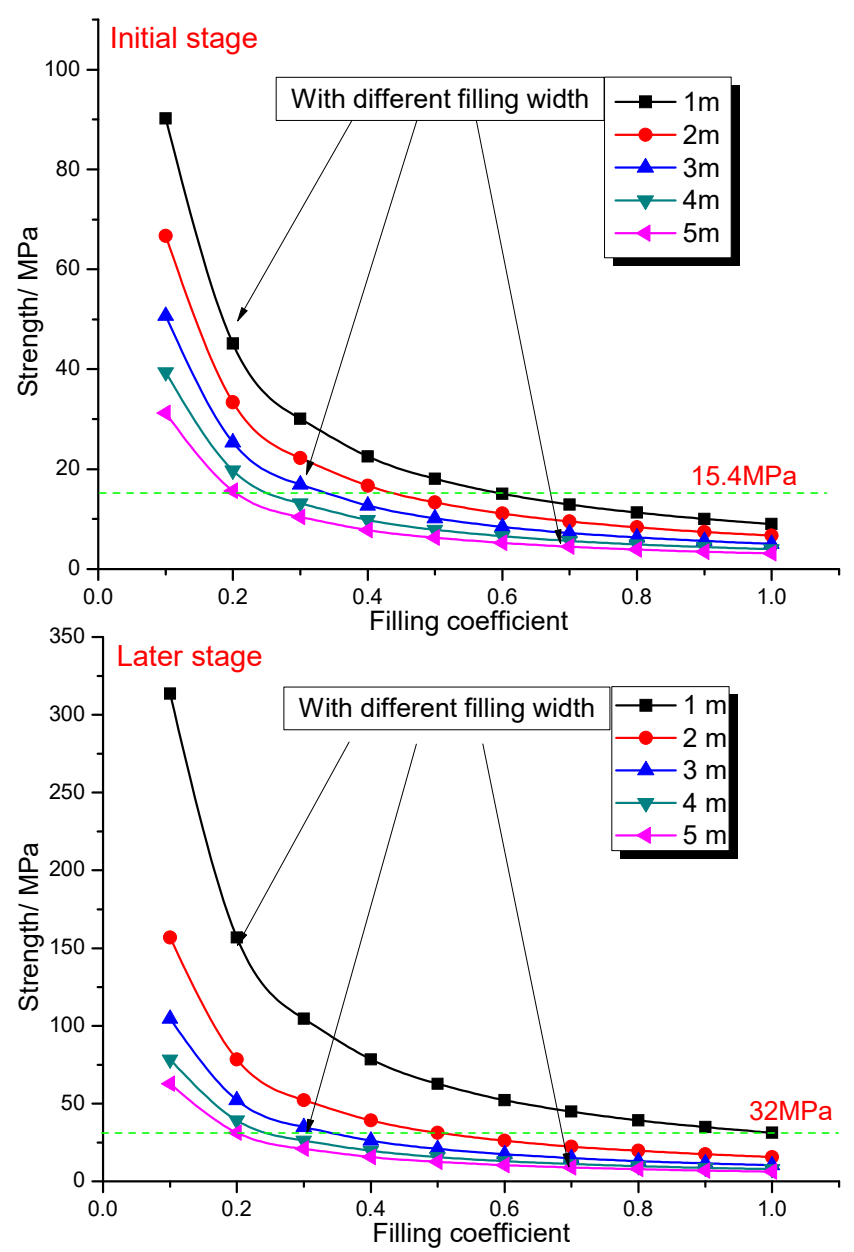

Figure 13. Theoretical strength for different width ratio matching.

\subsection{Deformation and Bearing Capacity Monitoring of Roadway and Filling Body}

The SRPF method can be used in some fields. Diagrammatic sketches of roadside filling with SRPF and the support structure among the filling body, plugging segment, and surrounding rock are shown in Figure 14.

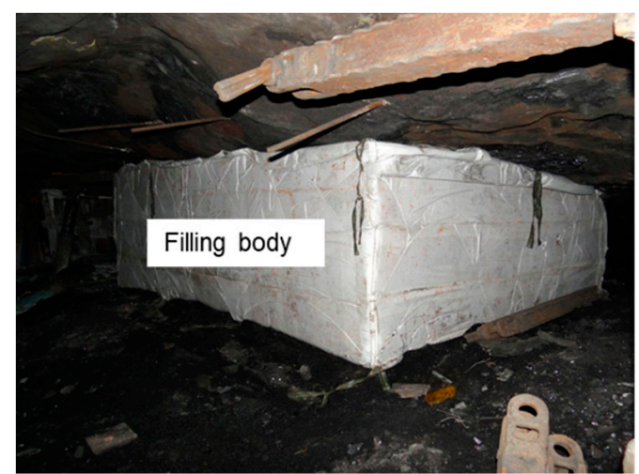

(a)

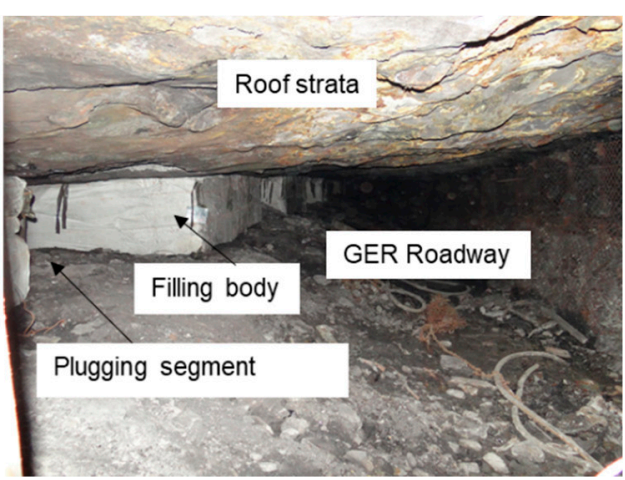

(b)

Figure 14. On-site roadside filling body. (a) Filling body diagram in Roadway(b) Forming roadway with filling body. 
The method has also been applied in the test stope. During the mining process, the stability of the filling body and surrounding rock can be measured and assessed by means of field monitoring. The monitoring of the surrounding rock of the roadway is based on the center line of the roof and floor, and a steel brazing material is used to penetrate straight into the floor. The bolt outcrop of the roadway section is taken as the measuring base point for both sides and the roof. The observation station arrangement is illustrated in Figure 15. When monitoring the height deformation of the filling body near the roadway, one point should be arranged in the direction perpendicular to the filling body and the top and bottom of the filling body. When monitoring the longitudinal and transverse deformation of the filling body, a horizontal casing with steel wire should be installed inside the filling body, and then the length change of the exposed steel wire should be measured.

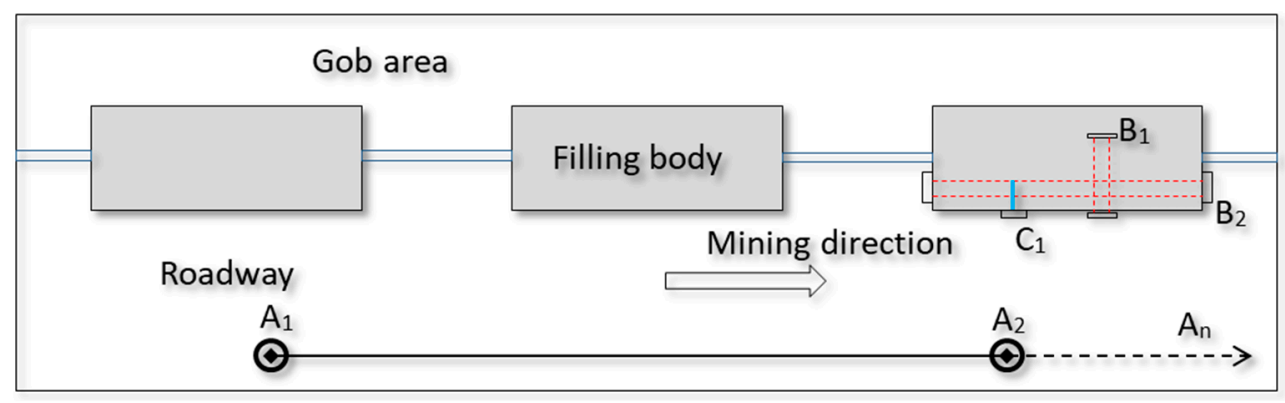

Figure 15. Schematic diagram of observation station arrangement.

For the test stope, the observed data of the SRPF roadway are illustrated in Figure 16. From the field observation data, it can be seen that the roof and floor of the roadway move between 0 and $160 \mathrm{~mm}$, and the deformation of the two sides is between 0 and $105 \mathrm{~mm}$. In the range of 0 to $20 \mathrm{~m}$ from the working face, the deformation rate of the roadway is low. In the range of 20 to $60 \mathrm{~m}$, the deformation rate is high. In the range of 60 to $100 \mathrm{~m}$, the deformation rate decreases, and the later deformation amount remains stable.

The deformation of the backfilling body can be divided into four stages. Within a range of 0 to $20 \mathrm{~m}$, the rotary subsidence of the roof rock beam is small, the pressure acting on backfilling body is low, the deformation of the backfilling body is smaller than that of the roadway because of the large initial support resistance of the backfilling body beside roadway, and the deformation speed is relatively slow. Within a range of 20 to $60 \mathrm{~m}$, the roof rock beam is subsides severely and the load on the backfilling body is met during this stage. The deformation rate of the filling body is faster and changes rapidly. After 60 to $100 \mathrm{~m}$, the working face advances a certain distance, the activity of the roof surrounding rock slows down, and the rotary subsidence is slower. Thus, the pressure of the filling body increases slowly, and the deformation rate of the filling body increases slowly. However, owing to the influence of the internal structure of the filling body, the strength of the filling body does not reach the maximum at this time. The shape rate increases occasionally. After $100 \mathrm{~m}$, the surrounding rock in the working face remains stable, the roof is supported by the filling body beside the roadway without being crushed, and the deformation rate is approximately zero.

According to the observation data and summary rules, the adaptability of a filling body and roadway to deformation is realized. However, owing to the adoption of the SRPF method to fill and retain roadways, there is a small amount of deformation in the lateral and vertical directions of the filling body, but the filling body can maintain stability without damage. It is further proved that the strength of filling body calculated by theoretical model can meet the production demand. The filling cost of mining can be decreased by $50 \%$, and the work efficiency can be improved by SRPF combined with a new grouting device. The long-term stability of the roadway proves that the calculated deformation $(38 \mathrm{~mm})$ is also reasonable. 


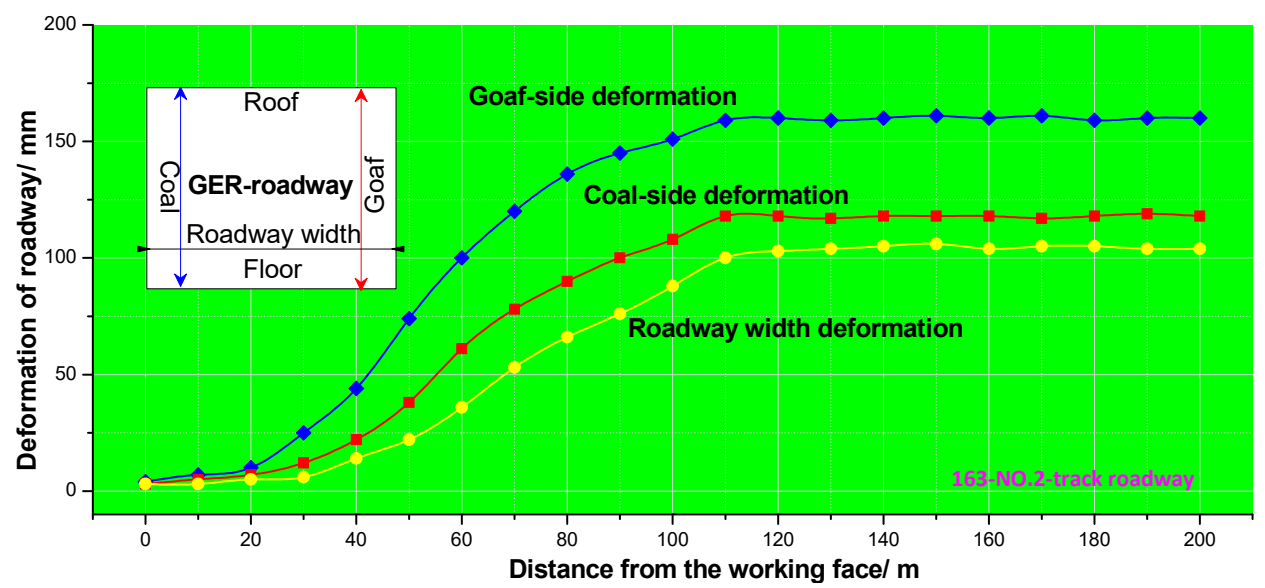

(a)

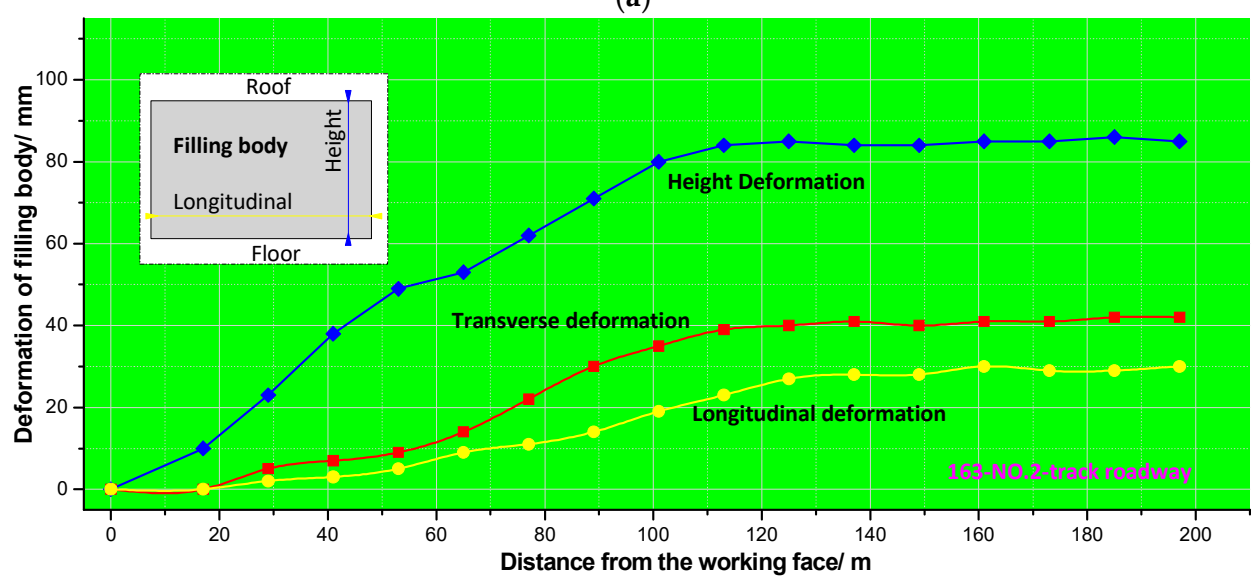

(b)

Figure 16. Field deformation observation: (a) deformation of roadway surrounding rock and (b) deformation of filling body.

\section{Discussion}

The SPRF method has changed the progress of traditional mining, which is combined with GER-WRF and GER-RF. Mining progress was designed and parameter formulas were obtained from mechanical models under the geological conditions. However, the application conditions of the method have a limitation of good stratum, and the bearing capacity of the supporting structure in the roadway has not been taken into account when the parameters are determined. Empirical formulas are used to calculate the uniformly distributed load and other parameters, which still need further study. In addition, grouting material, consisting of cement, gangue waste, fly ash, and so on, was added to the filling body. Considering the material shortage and high cost, new materials should be developed for complex conditions.

Influenced by environmental protection and energy shortage, the traditional mining methods of coal resources are gradually eliminated, and mining technologies adapted to various complex geological conditions should be created, especially for deep high stress and high heat mining conditions, and the appropriate mining equipment should be further improved. The mechanism of dynamic instability induced by excavation of deep high stress coal and rock mass should be further studied.

\section{Conclusions}

Based on current serious problems faced by the coal mining industry, a novel segmented roadside plugging-filling mining method (SRPF) was proposed. The cost can be reduced with the method under the conditions of mining safely. SRPF combines the existing gob-side entry retaining mining method, 
and used a coal mine in Shandong mining area as the background. The mining structure of a gob-side retaining roadway was innovatively reformed with this method, based on the newly defined roadside filling coefficient $\xi$. The implementation process was designed with a newly developed filling device. Moreover, the stope mechanical mechanism of SRPF was established with given models of initial cantilever beam subsidence bending, later parallel subsidence, and strike direction rock beam.

Taking the geological mining parameters of a mining stope as the background, the determination method for the filling mode under the SRPF mining method was further clarified. The selected filling material should be taken as the background parameter, and the trend curves of two stages under different models can be obtained according to the calculation formula of the filling strength. The suitable matching group is limited to the established threshold. Based on a model of internal stress field in coal seam mining and actual mining experience, the SRPF filling mode can be determined under the condition of low cost. It was determined that the mode of filling width, length, and filling coefficient was 2:2:0.5 for the test stope.

According to the theoretical deformation calculation, the theoretical long-term deformation value after the roadway completion was $\sim 38 \mathrm{~mm}$. Through on-site monitoring, the deformation value of the surrounding rock was $0-160 \mathrm{~mm}$ and that of the filling body was approximately $0-85 \mathrm{~mm}$. The support structure of a gob-side retaining roadway can maintain its stability and that of the surrounding rock by using the SRPF mining method. The entire process of safe mining on a working face further proves the rationality of this method, and the cost of mine-filling materials can be decreased by $50 \%$.

Author Contributions: Data curation, W.M., Z.D. and S.W.; Formal analysis, W.M. and L.L.; Funding acquisition, L.L. and Z.G.; Investigation, W.M.; Methodology, W.M. and L.L.; Resources, Z.G.; Validation, Z.G. and Z.D.; Writing—original draft, W.M.; Writing—review \& editing, L.L.

Funding: This research was funded by the National Key R\&D Program of China (grant no. 2018YFC0604706), the National Natural Science Foundation of China (grant nos. 51879041 and U1710253), the Fundamental Research Funds for the Central Universities (grant no. N180105029), and the Anhui Province Science and Technology Project of China (grant no. 17030901023). And the APC was funded by the National Natural Science Foundation of China (grant no. 51879041).

Conflicts of Interest: The authors declare no conflict of interest.

\section{Notation}

The following symbols are used in this paper:

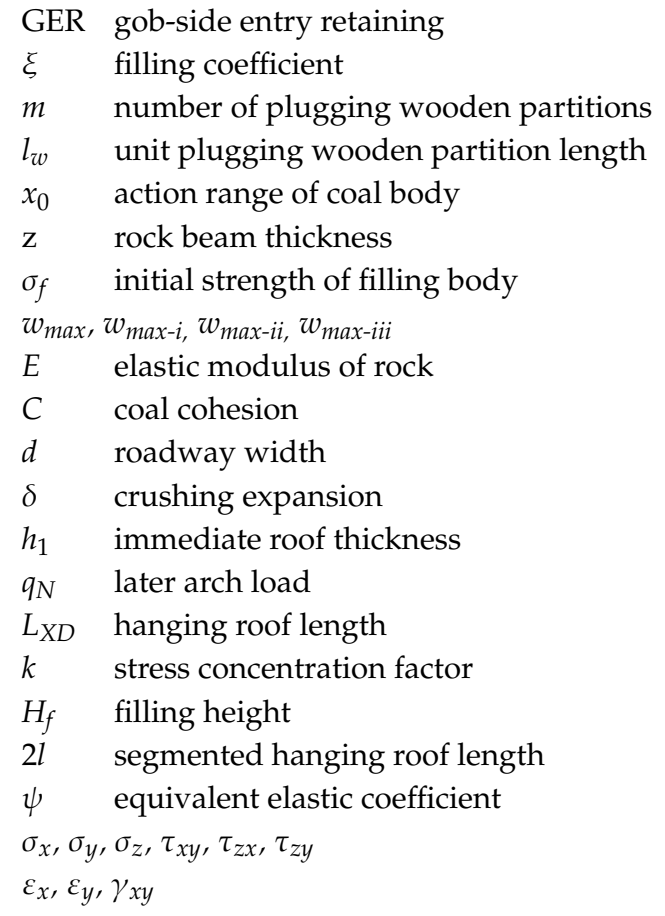

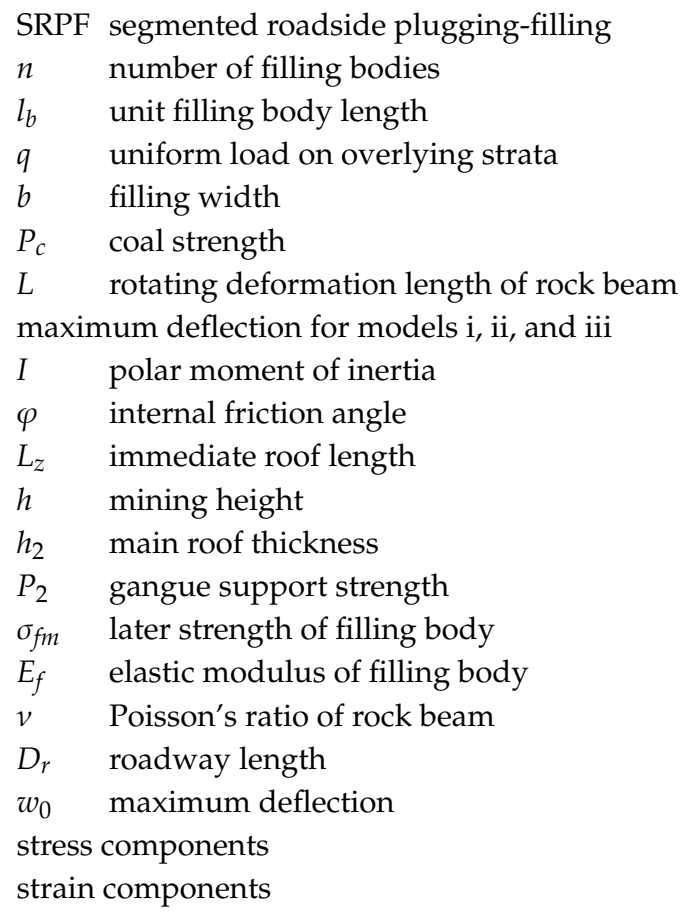




\section{References}

1. Lin, H.L.; Shi, Y.K. Research on walling-up with concrete block technology of gob-side entry retaining based on fully mechanized face in medium-thickness coal seam. Appl. Mech. Mater. 2012, 121-126, 2878-2882. [CrossRef]

2. Feng, G.R.; Wang, P.F.; Chugh, Y.P.; Zhao, J.L.; Wang, Z.Q.; Zhang, Z.P. A coal burst mitigation strategy for tailgate during deep mining of inclined longwall top coal caving panels at huafeng coal mine. Shock Vib. 2018, 2018, 1-18. [CrossRef]

3. Li, Z.L.; He, X.Q.; Dou, L.M.; Song, D.Z.; Wang, G.F. Numerical investigation of load shedding and rock burst reduction effects of top-coal caving mining in thick coal seams. Int. J. Rock Mech. Min. Sci. 2018, 110, 266-278. [CrossRef]

4. Zhang, D.S.; Miao, X.X.; Feng, G.M.; Song, Z.Q. Testing study on deformation features of surrounding rocks of gob-side entry retaining in fully-mechanized coal face with top-coal caving. J. China Univ. Min. Technol. 2003, 32, 232-235.

5. Gong, P.; Ma, Z.G.; Ni, X.Y.; Zhang, R.R. Floor heave mechanism of gob-side entry retaining with fully-mechanized backfilling mining. Energies 2017, 10, 2085. [CrossRef]

6. Jiang, L.S.; Zhang, P.P.; Chen, L.J.; Hao, Z.; Sainoki, A.; Mitri, H.S.; Wang, Q.B. Numerical approach for goaf-side entry layout and yield pillar design in fractured ground conditions. Rock Mech. Rock Eng. 2017, 50, 3049-3071. [CrossRef]

7. Yang, H.Y.; Cao, S.G.; Wang, S.Q.; Fan, Y.C.; Wang, S.; Chen, X.Z. Adaptation assessment of gob-side entry retaining based on geological factors. Eng. Geol. 2016, 209, 143-151. [CrossRef]

8. Liu, Y.K.; Zhou, F.B.; Liu, L.; Liu, C.; Hu, S.Y. An experimental and numerical investigation on the deformation of overlying coal seams above double-seam extraction for controlling coal mine methane emissions. Int. J. Coal Geol. 2011, 87, 139-149.

9. Wen, Z.J.; Jiang, Y.J.; Song, Z.Q.; Tang, J.Q. Study on mechanical model and surrounding rock catastrophe system of Gob-side retaining entry. J. Hunan Univ. Sci. Technol. 2011, 26, 12-16.

10. Tan, Y.L. Mining Pressure and Strata Control; Coal Industry Press: Beijing, China, 2008.

11. Yu, B.; Zhang, Z.Y.; Kuang, T.J.; Liu, J.R. Stress changes and deformation monitoring of longwall coal pillars located in weak ground. Rock Mech. Rock Eng. 2016, 49, 3293-3305. [CrossRef]

12. Yu, Y.; Deng, K.Z.; Luo, Y.; Chen, S.E.; Zhuang, H.F. An improved method for long-term stability evaluation of strip mining and pillar design. Int. J. Rock Mech. Min. Sci. 2018, 107, 25-30. [CrossRef]

13. Yin, D.W.; Chen, S.J.; Liu, X.Q.; Ma, H.F. Effect of joint angle in coal on failure mechanical behaviour of roof rock-coal combined body. Q. J. Eng. Geol. Hydrogeol. 2018, 51, 202-209. [CrossRef]

14. Shuang, H.Q.; Li, S.G.; Chen, G.F.; Xiao, P.; Shen, L.C.; Song, K.L. Influence mechanism of main roof height on surrounding rock stability of gob-side entry driving. Teh. Vjesn. 2018, 25, 492-501.

15. Chen, Y.; Bai, J.B.; Zhu, T.L.; Yan, S.; Zhao, S.H.; Li, X.C. Mechanisms of roadside support in gob-side entry retaining and its application. Rock Soil Mech. 2012, 33, 1427-1432.

16. Wang, A.L.; Ma, L.Q.; Wang, Z.W.; Zhang, D.S.; Li, K.; Zhang, Y.; Yi, X.J. Soil and water conservation in mining area based on ground surface subsidence control: Development of a high-water swelling material and its application in backfilling mining. Environ. Earth Sci. 2016, 75, 779. [CrossRef]

17. Wu, D.; Yang, B.G.; Liu, Y.C. Transportability and pressure drop of fresh cemented coal gangue-fly ash backfill (CGFB) slurry in pipe loop. Powder Technol. 2015, 284, 218-224. [CrossRef]

18. Gong, P.; Ma, Z.G.; Ni, X.Y.; Zhang, R.R. An experimental investigation on the mechanical properties of gangue concrete as a roadside support body material for backfilling gob-side entry retaining. Adv. Mater. Sci. Eng. 2017, 2018, 1-11.

19. Huang, P.; Spearing, A.J.S.; Feng, J.; Jessu, K.V.; Guo, S. Effects of solid backfilling on overburden strata movement in shallow depth longwall coal mines in west china. J. Geophys. Eng. 2018, 15, 2194-2208. [CrossRef]

20. Li, B.Y.; Ju, F. An experimental investigation into the compaction characteristic of granulated gangue backfilling materials modified with binders. Environ. Earth Sci. 2018, 77, 284. [CrossRef]

21. Zhang, G.C.; Tan, Y.L.; Liang, S.J.; Jia, H.G. Numerical estimation of suitable gob-side filling wall width in a highly gassy longwall mining panel. Int. J. Geomech. 2018, 18, 1-15. [CrossRef] 
22. Zhang, S.; Wang, X.F.; Fan, G.W.; Zhang, D.S.; Cui, J.J. Pillar size optimization design of isolated island panel gob-side entry driving in deep inclined coal seam—case study of Pingmei No. 6 coal seam. J. Geophys. Eng. 2018, 15, 816-828. [CrossRef]

23. Li, Z.L.; Dou, L.M.; Cai, W.; Wang, G.F.; Ding, Y.L.; Kong, Y. Roadway stagger layout for effective control of gob-side rock bursts in the longwall mining of a thick coal seam. Rock Mech. Rock Eng. 2016, 49, 621-629. [CrossRef]

24. Sun, C.D.; Zhang, D.S.; Wang, X.F.; Zhou, R. Large-size test on creep characteristics of high-water material for filling body beside roadway. J. Min. Saf. Eng. 2012, 29, 487-491.

25. Wang, X.F.; Zhang, D.S.; Sun, C.D.; Wang, Y. Surface subsidence control during bag filling mining of super high-water content material in the Handan mining area. Int. J. Oil Gas Coal Technol. 2016, 13, 87-102. [CrossRef]

26. Tan, Y.L.; Yu, F.H.; Ning, J.G.; Zhao, T.B. Adaptability theory of roadside support in gob-side entry retaining and its supporting design. J. China Coal Soc. 2015, 41, 376-382.

27. Tan, Y.L.; Yu, F.H.; Ning, J.G.; Zhao, T.B. Design and construction of entry retaining wall along a gob side under hard roof stratum. Int. J. Rock Mech. Min. Sci. 2015, 77, 115-121. [CrossRef]

28. Liu, X.S.; Ning, J.G.; Tan, Y.L.; Xu, Q.; Fan, D.Y. Coordinated supporting method of gob-side entry retaining in coal mines and a case study with hard roof. Geomech. Eng. 2018, 15, 1173-1182.

29. Bai, J.B.; Shen, W.L.; Guo, G.L.; Wang, X.Y.; Yu, Y. Roof deformation, failure characteristics, and preventive techniques of gob-side entry driving heading adjacent to the advancing working face. Rock Mech. Rock Eng. 2015, 48, 2447-2458. [CrossRef]

30. Zhang, Z.Z.; Bai, J.B.; Chen, Y.; Yan, S. An innovative approach for gob-side entry retaining in highly gassy fully-mechanized longwall top-coal caving. Int. J. Rock Mech. Min. Sci. 2015, 80, 1-11. [CrossRef]

31. He, M.C.; Gao, Y.B.; Yang, J.; Gong, W.L. An innovative approach for gob-side entry retaining in thick coal seam longwall mining. Energies 2017, 10, 1785. [CrossRef]

32. Wang, Q.; He, M.C.; Yang, J.; Gao, H.K.; Jiang, B.; Yu, H.C. Study of a no-pillar mining technique with automatically formed gob-side entry retaining for longwall mining in coal mines. Int. J. Rock Mech. Min. Sci. 2018, 110, 1-8. [CrossRef]

33. Ning, J.G.; Wang, J.; Bu, T.T.; Hu, S.C.; Liu, X.S. An Innovative Support Structure for Gob-Side Entry Retention in Steep Coal Seam Mining. Minerals 2017, 7, 75. [CrossRef]

34. Mu, W.Q. Research and application of gob-side entry retaining mining technology based on deformation mechanism of roadside backfill. Master's Thesis, Shandong University of Science and Technology, Qing Dao, China, 2017.

35. Li, H.M. Control design of roof rocks for gob-side entry. Chin. J. Rock Mech. Eng. 2000, 19, 651-654.

36. Han, C.L.; Zhang, N.; Li, B.Y.; Si, G.Y.; Zheng, X.G. Pressure relief and structure stability mechanism of hard roof for gob-side entry retaining. J. Cent. South Univ. 2015, 22, 4445-4455. [CrossRef]

37. Yin, D.W.; Meng, X.X.; Zhang, Z.Y.; Liu, B.C. Gob-side entry retaining formed by roof cutting without roadside support. Int. J. Oil Gas Coal Technol. 2018, 18, 467-484. [CrossRef]

38. Wen, Z.J.; Jing, S.L.; Song, Z.Q.; Jiang, Y.J.; Tang, J.Q. Study on coal face spatial structure model and control related dynamic disasters. Chin. J. Coal Sci. Technol. 2019, 47, 52-61.

39. Wu, J.L. Mechanics of Elasticity, 3rd ed.; Higher Education Press: Beijing, China, 2016; pp. 137-159.

40. Feng, F.; Li, D.Y.; Li, X.B.; Guo, Z.P.; Wang, S.F.; Chen, Y. Novel underhand cut-and-fill stoping method and mechanical analysis of overlying backfill. Int. J. Geomech. 2018, 17, 1-15. [CrossRef]

41. Gupta, A.K.; Paul, B. Comparative analysis of different materials to be used for backfilling in underground mine voids with a particular reference to hydraulic stowing. Int. J. Oil Gas Coal Technol. 2017, 15, 425-434. [CrossRef]

42. Ning, J.G.; Ma, P.F.; Liu, X.S.; Zhao, J.; Liu, W. Supporting mechanism of 'yielding-supporting' beside roadway maintained along the goaf under hard rocks. J. Min. Saf. Eng. 2013, 30, 369-374.

(C) 2019 by the authors. Licensee MDPI, Basel, Switzerland. This article is an open access article distributed under the terms and conditions of the Creative Commons Attribution (CC BY) license (http://creativecommons.org/licenses/by/4.0/). 